\title{
Promoting Social and Emotional Competencies in Early Childhood: Strategies for Teachers
}

\author{
Vicki Morkel and Tara McLaughlin
}

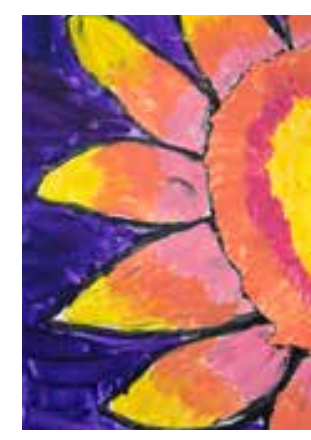

\begin{abstract}
This article discusses social and emotional competence and its importance in young children's development. Foundations for children's social and emotional competence are developed during the early years and are linked with school success and later-in-life well-being. We discuss three factors affecting children's social and emotional interactions and explore various strategies that teachers can use to promote the development of social and emotional competence. Strategies encourage teachers' active facilitation of supporting children's development and are grounded in strong positive relationships and supportive environments.
\end{abstract}

Keywords: Children, early years, emotional competence, social competence

\section{Practice paper}

\section{INTRODUCTION}

The early childhood environment is the milieu in which young children interact and form relationships with their peers and adults through play and learning activities. Social and emotional competence is needed to successfully navigate this environment and later-in-life environments. Social competence includes a combination of skills that support effective social interaction between a person and his or her environment (Lillvist, Sandberg, Bjorck-Akesson \& Granlund, 2009). Emotional competence involves understanding emotions in oneself and others as well as being able to control and express emotions appropriate to a situation in a way that is socially acceptable (Eisenberg, Cumberland \& Spinrad, 1998). Teachers and families support children to develop social and emotional competence through supportive and nurturing interactions, stimulating environments and learning opportunities, and promoting interactions with peers and siblings.

Ensuring early success in this area is critical. Research has shown that children's social and emotional competence in the early years of learning will influence school achievement and later-in-life well-being (National Council on the Developing Child, 2004; Shonkoff \& Phillips, 2000). Of note, the Dunedin Study, conducted in New Zealand, has shown that self-control - a key aspect of social and emotional competence in the early years - is associated with future achievements related to financial independence, physical health and positive emotional well-being and strong relationships with others (Moffitt, Poulton \& Caspi, 2013).

Moreover, international and national research has shown that children's experiences in early learning settings can have lasting effects on children's competencies later-in-life (Mitchell, Wylie \& Carr, 2008; Shonkoff \& Phillips, 2000). In short, what teachers do to support children's social and emotional competence matters. Given the importance of social and emotional competence and the need for teachers to actively support positive social and emotional development in young children, the Ministry of Education has promoted the Incredible Years Parent and Teacher Programmes created by Webster-Stratton and colleagues (Wetherall, 2014). Early research on the Incredible Years has shown that teachers have valued this training and the information they gain about how to support children's social and emotional competence (Fergusson, Horwood \& Stanley, 2013; Wooller, 2015).

The purpose of this article is to describe key aspects of children's developing social and emotional competence and provide ideas for early childhood educators to support children's social and emotional competence. In this article, social competence and emotional competence are described separately; yet, the inter-connectedness between these constructs in daily social environments should not be underestimated. We briefly discuss three factors that influence childrens encounters with the social world (culture, temperament and level of social interaction), before we introduce several strategies to support teachers' active facilitation of children's developing social and emotional competence. 


\section{Social Competence}

Social competence is made up of many different components. According to Lim, Rodger and Brown (2013), four key social skills dimensions are involved: learning related skills; compliance; interpersonal social skills, and group social-interaction. Learning related skills refers to skills which are necessary to support social interaction. These might include learning to pay attention, work in a group, follow directions, stay focused, persist with a task, and organise one's self. Compliance refers to how children adhere to rules, follow directions and exercise self-control. Interpersonal skills are used in interacting and making relationships with other children; these might include respecting others, sharing, responding with appropriate emotions, and showing empathy. Finally, group social-interaction refers to working with others in a group within the context of group norms and dynamics.

As children get older they are expected to engage in increasingly complex social interactions and settings. An important reminder for educators is that a child's social development takes place over time and requires on-going support. Although each child will have their own unique ways, there are key strategies that teachers and parents can use to support children in their social development and navigation of the social environment (Evans \& Harvey, 2012).

\section{Emotional Competence}

Emotional competence plays a vital role in children's social competence and vice-versa, yet it is characterised by different constructs. Emotional competence includes emotional expressiveness, emotion knowledge and emotional regulation (Denham et al., 2003). Related to emotional expressiveness, emotions are expressed in different ways with varying intensity. Children need to be able to suitably display their feelings in social interactions with peers and adults (Ashiabi, 2000). Emotion knowledge refers to understanding different emotions such that children are able to name, describe, and recognise emotions in one's self and others (Denham et al., 2003). When children are able to recognise emotions in those around them and understand or empathise with what others are feeling, they can respond in a fitting manner which can enhance their relationships (Ashiabi, 2000). Emotion regulation involves an awareness and modification of emotions according to the prevailing circumstances so that emotions are expressed appropriately (Denham, Bassett \& Zinsser, 2012). This involves active cognitive processes as multiple skills are involved. Children need to be aware of the social context as well as their own emotions and subsequent self-control.
Related to all areas of emotional competence, current research recommends that children should be permitted to feel and express their emotions. This includes encouraging positive emotion whilst also helping children to express and deal with negative emotions in a manner that is contextually acceptable. Again, these skills will develop over time and each child will have their own unique way, yet there are key strategies which teachers and parents can use to support children in their emotional development (Evans \& Harvey, 2012).

\section{Influences on Children's Social World}

Three key factors - culture, temperament and level of social interaction - influence children's encounters with the social world and their development of social and emotional competence. A brief review of considerations for teachers is provided.

\section{Culture}

Teachers should take cognisance of children's culture. Different cultures can emphasise different behaviours and styles of interaction. Teachers assessing social and emotional competence from their own cultural view might not understand children's capabilities for displaying appropriate behaviours (Barblett \& Maloney, 2010). The ways in which social and emotional competence is enacted in different cultures should be considered. For example, eastern cultures emphasise high levels of compliance and more cohesion, while western cultures have traditionally placed more emphasis on individualism (Lim, Rodger \& Brown, 2013). Through collaboration with families and communities, teachers can learn about the styles of interaction and the social and emotional skills that are valued and promoted. This can help teachers to better-support children in reaching their potential whilst maintaining their cultural identity.

\section{Temperament}

A child's temperament influences the way in which he or she interacts with the world (Mathieson \& Banerjee, 2010). Temperament refers to the way in which children tackle a task or approach a situation, and will have an impact on the types of experiences children seek to engage in (Keogh, 2003). This, together with life experiences, develops a personality which will affect self-concept, views about other people, personal values, attitudes, social interactions, and ways in which situations are dealt with (Rothbart, 2007). Rothbart (2007) has described three areas of temperament as Effortful Control, Negative Effect and Surgency/Extraversion. Children with more effortful control (attention span and self-control) 
play more interactively and positively with others. Those considered to have higher levels of surgency/ extraversion were more likely to join in with others and spend less time waiting to join in (Mathieson \& Banerjee, 2010). Children with negative effect tended to be less adaptable and expressed more negative mood (Walker, Berthelsen \& Irving, 2001). Temperament may influence both the amount and quality of social encounters with peers.

\section{Level of social interaction}

Children may have different levels of social interaction for different reasons (Coplan, Prakash, O'Neil \& Armer, 2004). Some factors might be within the child, such as conflicted shyness in which children want to participate but are too afraid to do so, or social disinterest in which children are not really motivated to play with others (Coplan \& Armer, 2005). Other factors might be external to the child, such as active isolation in which children play alone because others do not want to interact with them, or peer access in which children do not have regular access to peers or siblings for play. Helping children experience satisfying and successful interactions is likely to lead to children seeking out more social interactions.

\section{Implications for teachers}

Each child is unique and each child will need different types of experiences and supports to maximise their social and emotional competence. By knowing the children in their care, pre-school teachers can plan suitable learning experiences, build on children's strengths, provide support, and create situations conducive to ensuring all children have quality social interactions with others and engage in emotional experiences in ways that are responsive to their unique identities, including the child's culture, temperament, and prior level of social interaction. When teachers know children well, they can often anticipate potential problem situations and intervene with positive guidance to help to maintain a positive environment (Keogh, 2003).

\section{Strategies for Promoting Children's Social and Emotional Competence}

The development of social and emotional competence in young children has been linked to be both academic and social school-readiness in children (Raver \& Knitzer, 2002). Those competent in these areas seem to perform better at school and have enthusiasm, perseverance and positive approaches towards learning (Ziv, 2013). Teachers can support children in their endeavours to become socially and emotionally competent by providing a high-quality environment, and teaching essential social and emotion skills to support children's interaction and social behaviours (Joseph \& Strain, 2003). To support teachers on this journey, we describe strategies for teachers to promote a positive social environment, and specific skills and strategies that support children's confidence and competence.

At the core of our recommendations is teacher-child relationships. High-quality relationships between teachers and children provide a secure foundation from which children can express their emotions and explore relationships with their fellow peers (Howes \& Ritchie, 2002). To build strong relationships with children, teachers might get to know children's interests and preferences, get to know children's families and home life routines, use children's and parents' names when interacting, ask children questions and really listen to their answers, share information about themselves, and have clear, fair, and consistent expectations and boundaries that are communicated to children. Children learn best in the context of warm, positive, respectful, caring and responsive relationships (Evans \& Harvey, 2012). Teachers need to actively develop their relationships with young children and their families (Bary, 2010).

\section{Creating a Positive Climate}

Setting a positive climate helps children feel safe and secure in their environment. Climate refers to the prevailing mood, attitudes and tone that teachers, families and children feel when they are in the early childhood setting. When there is a positive climate and children feel good, they are more likely to interact with others (Denham et al., 2003). Teachers can take active steps to create a positive climate. Han and Kemple (2006), for example, suggest that the physical environment might include various places of interest where children are able to interact in small groups as well as other more private places where they can go to regulate themselves and/or have time on their own.

Salminen, Hannikainen, Poikonen and RaskuPuttonen (2014) suggest ways for grouping children, such as working together in pairs or small groups, can influence the social climate. Small group activities can help children to develop the skills for interacting with others in large groups. Group cohesion can be promoted when teachers remind children of the shared group expectations or rules, what would be fair, how the group works, and refer back to established group expectations. Positive group dynamics are enhanced when children are allowed to take on a leadership or active role where they listen and learn from each other. Careful considerations of groupings and active facilitation of group 
cohesiveness can support children in their sense of belonging.

Promoting social values and an awareness of other cultures can also support a positive climate (Han \& Kemple, 2006). Social values (or virtues) might include kindness, honesty, respect, social justice or fairness, responsibility, empathy and caring for others. These can vary within different cultures. Teachers, in collaboration with families and community, might consider selecting different social values and teaching them explicitly. Social reinforcement of identified values can be used when children display socially-desired behaviours to encourage the chance of them being repeated (Han \& Kemple, 2006). Teachers might, for example, take a few weeks to focus on respect, plan different activities to promote and reinforce this value in the context of meaningful activities for children, before spending a few weeks introducing and focusing on a new value.

To support an awareness of other cultures, similarities and differences should be acknowledged, respected and celebrated to foster a climate of tolerance and respect. When teachers are seen to show appreciation of diversity in others, it serves as a role-model for children to interact with others who they consider to be different from them in some way or other (Vuckovic, 2008). This is particularly important in the Aotearoa/New Zealand context as schools serve children and families from many different cultures, languages and ethnicities. It is also important for teachers to "know themselves" and be aware of how their personal background, culture, temperament and characteristics will affect their relationships with others (Keogh, 2003). Related to supporting children's positive behaviours, it might be helpful for teachers to reflect on the behaviours they personally have little tolerance for or test their patience. Identifying these behaviours can help teachers and teams to have a plan for responding appropriately and consistently in everyday situations.

Finally, establishing positive relationships with other adults in the setting is key. This includes relationships with teaching teams and with families. Teachers' relationships with team members will affect centre climate such that teachers act as role models for children. As noted by Farquhar (2003), teachers' behaviours and attitudes towards their colleagues will affect the children's relationships and behaviours with their own peers. Moreover, teachers' relationships with families - ensuring families feel welcome, learning about the family and showing genuine concern for their child - can contribute to a positive climate. In addition, parent-teacher communication can support consistency across environments for children. Teachers might share what they are working on at school while parents might share key issues from home so each can continue to work on these skills and concepts in supportive ways for the child. Strong teacher-parent relationships assist greatly if there is a need to discuss challenging situations or events with parents regarding their child. Sharing resources and ideas is a great way to support families to support their own child's social and emotional competence.

\section{Skills and Strategies}

There are several key skills that teachers can help children develop to become socially and emotionally competent. For example, teachers can help children build confidence and develop a positive self-identity. It is important to note that confidence and positive self-identity are learnt skills which develop over time (Willis \& Schiller, 2011). Strategies to build confidence include providing positive experiences for children and ensuring children receive positive responses from others. When children are encouraged to try new things and their successes are recognised, self-confidence develops (Willis \& Schiller, 2011). Related to confidence, teachers can help children to develop a positive self-identity. Teachers foster a sense of self-worth by the way they show respect for children and build them up in a positive and authentic way. This might include letting children know about the things that you think makes them interesting and unique, asking children to talk about what they like about themselves, and modelling a positive self-identity by talking about what you like about yourself.

Self-control is another important skill for children to develop. Self-control assists children to make good choices and respond in suitable ways to situations (Willis \& Schiller, 2011). To support children with self-control, teachers might model keeping calm, describing what to do to remain in control, and sharing how they handle their emotions in various situations (Willis \& Schiller, 2011). Teachers also might involve children in setting some achievable expectations or rules that teachers and children can follow and then acknowledge children when they follow rules in situations that children might be likely to "break" the rules.

In addition to the more dynamic skills such as confidence and self-control, children can be taught essential social skills from an early age. Teaching children how to wait for their turn, ask a peer to play, share toys, or tell peers in a kind way if they do not want to play or share at the moment can support positive social interactions with peers and adults (Johnson, Ironsmith, Snow \& Poteat, 2000). To support these types of skills, teachers might describe 
or model different ways to get along with friends, support children in interactions to use different social skills, and comment when they see children using skills in ongoing activities and routines.

Related to emotional competence, teachers are "important socializers of emotion" (Denham et al., 2012, p.140). The ways teachers manage their own emotions will affect how children handle and socialise their own emotions (Denham et al., 2012). Emotional scaffolding can be used in assisting children to learn about emotions. Teachers might, for example, teach children how to identify feelings in themselves and others, solve problems, express their anger in appropriate ways or calm down (Fox \& Lentini, 2006). These skills might be demonstrated using modelling, drama and puppets before children are given the opportunity to try them out in everyday interactions. The Incredible Years Programme suggests using puppets or action dolls to explore ways to solve 'make believe' problems or likely social situations such as greeting a child, showing interest in someone else or requesting assistance to help children practise skills with support (Webster-Stratton, 1999). As children try out new skills they might need verbal coaching, reassuring gestures, or prompting questions or reminders about what to do until they become fluent with their skills. As children increase in confidence and competence, direct support can be faded and teachers might use other strategies to continue to acknowledge children's positive social and emotional interactions.

Communication is a related and often underemphasised skill for social and emotional competence. Yet a child's ability to receive information (receptive communication) and express their wants, needs and feelings (expressive communication) is critical in social interactions. Willis and Schiller (2011) suggest teachers assist children by developing their listening skills and an awareness of body language and voice tone. Teachers can promote proficiency by modelling active-listening and helping children recognise what different social cues might mean. For expressing themselves, children need a rich vocabulary that includes key words for playing with others, making friends, and sharing emotions. Reading books that help children learn about different social situations, making friends, and different emotions can be a great way to introduce new vocabulary. Teachers might also make sure to use friendship words, emotion words, and other related words in everyday interactions with children.

Strategies and ideas described in this article can support teachers to help all children develop the skills they need for social and emotional competence.
None-the-less, for some children, more intervention might be required. When children have persistent difficulty with social interactions or challenging behaviour then individualised interventions might need to be put into place (Fox \& Lentini, 2006). Early childhood teachers should seek additional support (e.g. local administrative support, Group Special Education services) when children need additional assistance.

\section{CONCLUSION}

The development of social and emotional competence is instrumental in children experiencing success within their social interactions in early childhood and being ready for school (Ziv, 2010). Understanding the complex skills that children need to display social and emotional competence can aid teachers to support children in this area. Teachers should review the social environment regularly to ensure that strategies are in place to cater for and accommodate the diverse personalities of children attending. It is important for teachers to know their children well and use strategies that build on children's strengths to support the development of new skills. The creation of a positive social environment, where there is mutual trust and respect, forms the backdrop where children can be supported as they practise and develop social and emotional competence.

\section{REFERENCES}

Ashiabi, G.S. (2000). Promoting the emotional development of preschoolers. Early Childhood Education Journal, 28(2), 79-84.

Barblett, L., \& Maloney, C. (2010). Complexities of assessing social and emotional competence and wellbeing in young children. Australasian Journal of Early Childhood, 35(2), 13-18.

Bary, R. (2010). It's all about relationships: Infant and toddler pedagogy. Nga Tau Tuatahi. New Zealand Journal of Infant and Toddler Education, 12(2), 1518.

Coplan, R.J., \& Armer, M. (2005). Talking yourself out of being shy: Shyness, expressive vocabulary, and socioemotional adjustment in preschool. MerrillPalmer Quarterly, 51(1), 20-41.

Coplan, R.J., Prakash, K., O’Neil, K., \& Armer, M. (2004). Do you "want" to play? Distinguishing between conflicted shyness and social disinterest in early childhood. Developmental Psychology 40(2), 244-258.

Denham, S.A., Bassett, H.H., \& Zinsser, K. (2012). Early childhood teachers as socializers of young children's emotional competence. Early Childhood Education Journal 4O(3), 137-143. 
Denham, S., Blair, K.A., DeMulder, E., Levitas, J., Sawyer, K., Auerbach-Major, S., \& Queenan, P. (2003). Preschool emotional competence: Pathway to social competence? Child Development 74(1), 238-256.

Evans, I. M., \& Harvey, S. T. (2012). Warming the emotional climate of the primary school classroom. Auckland, New Zealand: Dunmore Publishing.

Farquhar, S. (2003). Quality teaching early foundations: Best evidence synthesis (June 2003).Wellington, New Zealand: Ministry of Education.

Fergusson, D.M., Horwood, L.J. \& Stanley, L. (2013). A preliminary evaluation of the incredible years teacher programme. The New Zealand Journal of Psychology, 42, 51-56.

Fox, L., \& Lentini, R.H. (2006). "You Got It!" Teaching social and emotional skills. Young Children, 61(6), 36-42.

Han, H.S., \& Kemple, K.M. (2006). Components of social competence and strategies of support: Considering what to teach and how. Early Childhood Education Journal, 34(3), 241-246.

Howes, C., \& Ritchie, S. (2002). A matter of trust connecting teachers and learners in the early childhood environment. New York, USA: Teachers College Press.

Joseph, G.E., \& Strain, P.S. (2003). Comprehensive evidence-based social-emotional curricula for young children: An analysis of efficacious adoption potential. Topics in Early Childhood Special Education, 23(2), 65-76.

Johnson, C., Ironsmith, M., Snow, C.W., \& Poteat, G.M. (2000). Peer acceptance and social adjustment in preschool and kindergarten. Early Childhood Education Journal 27(4), 207-212.

Keogh, B.K. (2003). Temperament in the classroom. Baltimore, Maryland: Paul H. Brookes Publishing Co.

Lillvist, A., Sandberg, A., Bjorck-Akesson, E., \& Granlund, M.( 2009). The construct of social competence - How preschool teachers define social competence in young children. International Journal of Early Childhood, 41(1), 51-68.

Lim, S.M., Rodger, S., \& Brown, T. (2013). Model of social competence in an early childhood environment. Occupational Therapy in Mental Health, 29(2), 114-133.

Mathieson, K., \& Banerjee, R. (2010). Pre-school peer play: The beginnings of social competence. Educational \& Child Psychology, 27(1), 9-20.

Mitchell, L., Wylie, C., \& Carr, M. (2008). Outcomes of early childhood education: Literature review. Ministry of Education Report. Retrieved from: http:// www.nzcer.org.nz/system/files/885_Outcomes.pdf
Moffitt, T., Poulton, R., \& Caspi, A. (2013). Lifelong impact of early self-control. American Scientist, 101(5), 352-359.

National Council on the Developing Child (2004). Young children develop in an environment of relationship: Working paper no. 1. Retrieved from http://www.developingchild.net/pubs/wp.html.

Raver, C.C., \& Knitzer, J. (2002). Ready to enter: What research tells policymakers about strategies to promote social and emotional school readiness among three- and four- year- old children. New York: National Council on Children in Poverty. Retrieved from: http://www.nccp.org/publications/ pdf/text_485.pdf

Rothbart, M.K. (2007). Temperament, development, and personality. Psychological Science, 16(4), 207-212.

Salminen, J., Hannikainen, M., Poikonen, P., \& RaskuPuttonen, H. (2014). Teachers' contribution to the social life of Finnish preschool classrooms during structured learning sessions. Early Child Development and Care, 184(3), 416-433.

Shonkoff, J., \& Phillips, D. (2000). From neurons to neighborhoods. Washington, DC: National Academy Press.

Vuckovic, A. (2008). Making the multicultural learning environment flourish: The importance of the child-teacher relationship in educating young children about diversity. Australian Journal of Early Childhood, 33(1), 9-16.

Walker, S., Bertelsen, D., \& Irving, K. (2001). Temperament and peer acceptance in early childhood: Sex and social differences. Child Study Journal 31(3), 177-191.

Webster-Stratton, C. (1999). How to promote children's social and emotional competence. Thousand Oaks, CA: Sage.

Wetherall, M. (2014). Incredible years parent and teacher programmes: Emerging issues and trends. Kairaranga, 15, 34-39.

Willis, C.A., \& Schiller, P. (2011). Preschoolers social skills steer life success. Young Children, 66(1), 4249.

Wooller, S. (2015). Early childhood teachers perceptions of the social validity of the incredible years teacher classroom management programme in Aotearoa/ New Zealand. Thesis in preparation. Massey University, Palmerston North, New Zealand.

Ziv, Y. (2013). Social information processing patterns, social skills, and school readiness in preschool children. Journal of Experimental Child Psychology 114(2), 306-320. 


\section{AUTHOR PROFILES}

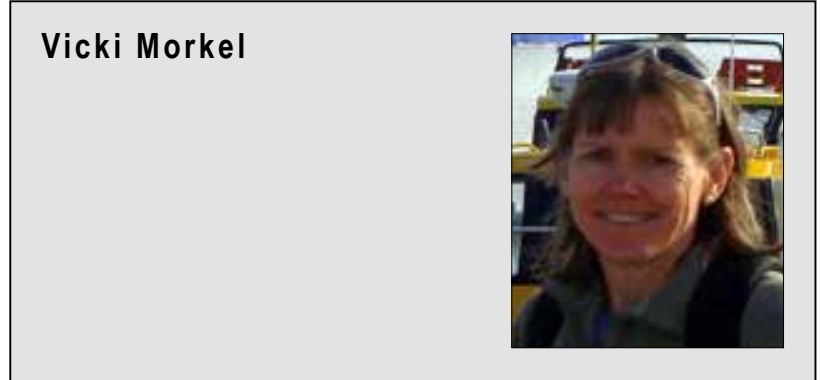

Vicki Morkel is a preschool teacher and supervisor at an early childhood centre in Auckland. After several accounting roles she returned to her initial career choice of teaching. Vicki is currently studying towards a masters degree in early childhood education at Massey University. She considers herself extremely privileged to be able to work with young children and be a part of their lives.

\section{Email:}

vicki.morkel@vodafone.co.nz

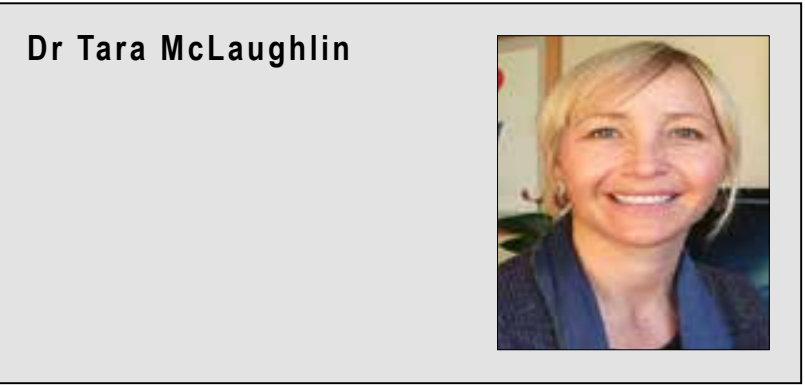

Dr Tara McLaughlin is a senior lecturer in the Institute of Education at Massey University. She has worked with young children and children with disabilities in inclusive learning settings in the United States and in New Zealand. As a teacher, teacher educator, and researcher in Early Years, she is committed to supporting learning environments that promote diverse and equitable opportunities for all children and families.

\section{Email:}

t.w.mclaughlin@massey.ac.nz 